\title{
PECULIARITIES OF HEAT-MASS-EXCHANGE PROCESSES IN FACES DEVELOPING STEEP COAL SEAMS
}

\author{
Vadim R. Alabyev ${ }^{1}$, Marat L. Rudakov², Mariia A. Korobitcyna ${ }^{3}$ \\ ${ }_{1,2,3}$ Industrial Safety Department \\ Saint Petersburg \\ Mining University \\ 199106, 21 Line Vassilievsky Isl., \\ Saint Petersburg, RUSSIAN FEDERATION
}

\begin{abstract}
The paper shows the need for increasing accuracy of heat calculations in choosing chilling equipment for normalization of temperature conditions in working faces. The biggest error in prediction of temperature conditions is revealed in calculations of air temperature in faces developing steep coal seams, which is related to the peculiarities of technological processes taking place in excavation of coal. In the present work we have determined difference of heat-exchange processes between fossils and air within faces during development of steep flat and sloping coal seams. In faces with flat and sloping occurrence of seams the coal on conveying unit is considered a half-closed body, the surface of which provides convective heat exchange with air. At the same time, in face with steep occurrence of seams, where delivering of material is affected by gravity force, one should consider convective heat exchange of coal fraction within the air stream. There is a mathematical model for convective heat exchange between air and fossil in faces that develop steep coal seams, which includes a number of simplifying assumptions as well. Besides, there are engineering methods for calculation of heat emission from coal within faces under border condition of first and third types. There is also a new approach for recognition of heat transferring surfaces from a coal seam and developed space as for faces using pneumatic hammer and combining technologies of coal extraction. Based on the results of the research, assessment of the impact of heat emission from coal on the air temperature within longwall faces developing steep seams is given.
\end{abstract}

$\begin{array}{lr}\text { Received: } & \text { April 4, } 2017 \\ \text { Revised: } & \text { April 24, } 2017 \\ \text { Published: } & \text { May 8, } 2017 \\ \text { Correspondence } & \text { author }\end{array}$

Received: $\quad$ April 4, 2017

Revised: $\quad$ April 24, 2017

Correspondence author 
AMS Subject Classification: 03C01, 53B02, 34A01

Key Words: mine, steep seams, longwall face, coal, temperature, temperature conditions, prediction methods, the coefficient of nonstationary heat exchange

\section{Introduction}

Normalization of temperature conditions in mine workings is quite a relevant task just as from the viewpoint of accidents' prevention, so from a perspective of improving employers' working conditions. At the current time in countries of Commonwealth of Independent States the prediction of temperature of air in coal mines is performed with both - analytical and numerical methods. Of special note is the method [1] developed on the basis fundamental researches [2] that serves as the base for development of various automated methods for predicting temperature conditions in mine workings of different purposes. [3, 4]. According to the results of air temperature prediction the cooling demand of working areas is defined and the selection of corresponding chilling equipment for normalization of temperature conditions at that areas is performed [5]. For cooling of air at working places both - underground chilling systems with mining explosion-proof design $[6,7,8]$ and the systems with surface arrangement of chilling stations using modern technologies on transfer of cold to bigger depths [9] are applied. Upon such condition the role of heat calculations grows, as far as their accuracy defines the power of chilling equipment.

The long-term field approbation of calculated dependences listed in [1] showed the biggest error in prediction of temperature conditions is revealed in calculation of air temperature in faces developing steep coal seams. It is related to the fact the mines developing such seams are characterized with bigger variety of extraction technologies, than the mines developing flat and sloping seams.

One of the factors influencing formation of temperature conditions of working faces is heat emissions from hewed fossil. However for mines developing steep coal seams the question remains insufficiently explored. This is stipulated with the fact the heat exchange between air and the fossil within faces of steep and flat seams possesses significant difference. Thus, within flat seams the coal on conveyor unit is considered a half-closed body, and the air flow passes over the surface of bulk mass, as a result of which the convective heat exchange between coal and air is provided only for surface of the mass. At the same time within faces of steep seams using pneumatic hammer or combining extraction technology every fraction of hewed coal moving under gravity forces is bathed 
with air stream providing the heat exchange with air in face takes place over the entire surface of coal pieces. In this case we should consider convective heat exchange of fraction in the stream. Under such conditions the surface of heat exchange between coal and air in steep faces is about 10 times bigger, than when developing flat and sloping seams, which provides significant intensifying of the process of heat emission by hewed coal.

The steep seams are mostly peculiar to overhead form of working face. In case of use combining and especially pneumatic hammer extraction of coal the general front of such faces possesses quite a complicated configuration. Particularly, in case of 120-140 m. long face and presence of benches within it the actual heat transferring surface of coal seam is much bigger, than it is considered in [1]. In addition, when speaking about such faces one usually doesn't take into account specific features of air heat exchange, which are being peculiar to the method of smooth dipping with retention of coal on cogs exposed roof. The method of smooth lowering or retention of exposed roof. In connection with this the validity of prediction of air temperature at its output from face reduces.

\section{Mathematical Model}

\subsection{Emissions of fossil's heat in faces}

The process of thermal interference between coal falling under the effect of gravity force and air in steep faces using combining or pneumatic hammer extraction of coal is of unsteady character. This is stipulated with change of temperature field within pieces of hewed coal during its cooling. The diagram of the face with steep bedding of seam is represented in fig. 1 .
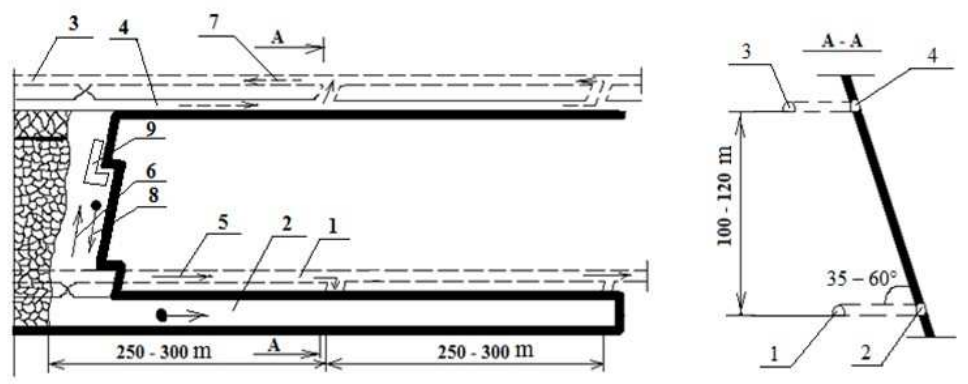

Figure 1: The diagram of steep bedding face: 1 - field haulage drift; 2 haulage; 3 - field ventilation drift; 4 - ventilation drift; 5 - intake air; 6 - air 
stream for face ventilation; 7 - return ventilation air; 8 - direction of hewed coal movement; 9 - combine.

When defining the task of unsteady convective heat exchange between hewed coal and the air the following assumptions are accepted:

1 ) the pieces of coal have the form of sphere, the average radius of which is equal to $R$;

2) the average temperature of air within face $t$ is constant;

3) the start of heat exchange between coal and air in the face takes place when $\tau_{0}>0$, where $\tau$ - the time of heat transfer of coal in face, $s$;

4) initial distribution of temperature in sphere makes $T\left(r, \tau_{0}\right)=T_{0}=$ const, where $T_{0}$ - the temperature of rocky massif at the depth of the development, ${ }^{\circ} \mathrm{C}$;

$5)$ the speed of coal pieces' movement within the face is being constant and depends on the angle of seam's slope: $V_{i}=f(\psi)=$ const, where: $V_{i}$ - the speed of coal movement, m/s; $\psi$ - the angle of seam's slope, deg.

The mathematical formulation for the set task is represented with differential equation of heat exchange [10]:

$$
\frac{\partial T}{\partial \tau}=a \cdot\left(\frac{\partial^{2} T(r, \tau)}{\partial r^{2}}+\frac{2 \partial T(r, \tau)}{2 \partial r}\right),\left(\tau_{0}>0 ; 0<r<R\right)
$$

where $a$ - the coal temperature conductivity coefficient, $\mathrm{m}^{2} / \mathrm{s}$.

When solving practical tasks there are border conditions of both - the first:

$$
T_{\text {sur }}=f(x, y, z, \tau), \alpha \rightarrow \infty
$$

and the third types:

$$
-\lambda\left(\frac{\partial T}{\partial r}\right)=\alpha\left(T_{\text {sur }}-t\right), \alpha>0
$$

where $T_{\text {sur }}$ the coal temperature at surface, ${ }^{\circ} \mathrm{C}$;

$\alpha$ - the heat transfer coefficient of coal, $W /\left(m^{2} \cdot{ }^{\circ} C\right)$;

$\lambda$ - the coefficient of coal heat conductivity, $W /\left(m \cdot{ }^{\circ} \mathrm{C}\right)$.

The general solution of differential equation (1) under border conditions of first and third types is represented as follows [10]:

$$
T(r, \tau)=\left(T_{0}-t\right) \sum_{n=1}^{\infty} A_{n} \frac{R \sin \left(\mu_{n} \frac{r}{R}\right)}{r \mu_{n}} \exp \left(-\mu_{n}^{2} F_{0}\right)+t,
$$

where $F_{0}$ - the Fourier number; 


$$
F_{0}=\frac{a \tau}{R^{2}}
$$

The value $A_{n}$ under border conditions of third type is calculated with the dependence [10]:

$$
A_{n}=(-1)^{n+1} \frac{2 B i \sqrt{\mu_{n}^{2}}+(B i-1)^{2}}{\mu_{n}^{2}+B i^{2}+B i},
$$

where $\mu_{n}$ - the root of characteristic equation;

$B i$ - the Bio criterion.

$$
\begin{gathered}
\operatorname{tg} \mu=-\frac{\mu}{B i-1}, \\
B i=\frac{\alpha R}{\lambda} .
\end{gathered}
$$

The specific heat flow $\left(q_{0}\right)$ is defined with Fourier's law:

$$
q_{0}=-\lambda\left(\frac{\partial T}{\partial r}\right)
$$

Using the differential equation (7), which is added with values $T(r, \tau)$ from equation (2), we have:

$$
q_{0}=-\frac{\lambda\left(T_{0}-t\right)}{R} \sum_{n=1}^{\infty} A_{n} \cos \mu_{n} \exp \left(-\mu_{n}^{2} F_{0}\right) .
$$

The equation (8) represents the expression for specific heat flow from pieces of coal of spherical form for time $\tau$. Since the time of coal cooling in face changes from $\tau_{0}$ to $\tau$, after integration equation (8) from $\tau_{0}$ to $\tau$ and dividing the obtained equation by $\tau$ we get:

$$
q_{0}=\frac{\lambda R}{a \tau}\left(T_{0}-t\right) \sum_{n=1}^{\infty} \frac{A_{n}}{\mu_{n}^{2}} \cos \mu_{n}\left[\exp \left(-\mu_{n}^{2} F_{0}\right)-\exp \left(-\mu_{n}^{2} \frac{a \tau_{0}}{R^{2}}\right)\right]
$$

In such a way, the equation (9) is the solution for defining averaged integral heat flow from a unit of surface of spherical body with temperature difference of $1{ }^{\circ} \mathrm{C}$ for the time $\tau$. Next, we enter designations:

$$
\theta=\sum_{n=1}^{\infty} \frac{A_{n}}{\mu_{n}^{2}} \cos \mu_{n}\left[\exp \left(-\mu_{n}^{2} F_{0}\right)-\exp \left(-\mu_{n}^{2} \frac{a \tau_{0}}{R_{2}}\right)\right]
$$




$$
k_{\tau l}=\frac{\lambda R}{a \tau} \theta
$$

the equation (9) takes the form of:

$$
q_{0}=k_{\tau l}\left(T_{0}-t\right)
$$

where $k_{\tau l}$ is the coefficient of unsteady nonstationary heat exchange between coal and air stream within face.

$$
k_{\tau l}=\frac{\lambda R}{a \tau} \sum_{n=1}^{\infty} \frac{A_{n}}{\mu_{n}^{2}} \cos \mu_{n}\left[\exp \left(-\mu_{n}^{2} F_{0}\right)-\exp \left(-\mu_{n}^{2} \frac{a \tau_{0}}{R^{2}}\right)\right]
$$

Applying of the equation (13) in heat calculations remains rather difficult, therefore for engineering calculation we on the basis of regression analysis have derived the following empirical dependence for border conditions of third type:

$$
k_{\tau l}=\frac{\lambda R}{a \tau} 0,383 F_{0}^{0,64} \ln B .
$$

The solution of equation (5) under conclusion (14) has been performed with numerical method. The right part of the equation (10) represents the sum of components of convergent series, the number of which depends on value of criteria $F_{0}$ and $B i$, i.e. - on the size of coal pieces, cooling time and relative velocity of air flow. The number of considered components of equation (10) makes from 7 to 9 , which is the maximum, the defined correlation factor in such a case is equal to 0,997. The formula (14) is being true for criterion $F_{0}$ within the limits from 0,001 to 0,25 and the criterion $B i$ from 1 to 10, which corresponds to conditions taking place in mines with steep occurrence of seams.

However, if the coal surface is wet $(\alpha \rightarrow \infty)$, which corresponds to border conditions of first type, the equation for $\mu_{n}$ and $A_{n}$ will possess the following form $[10]$ :

$$
\begin{gathered}
\mu_{n}=n \pi, \\
A_{n}=(-2)^{n+1} .
\end{gathered}
$$

In such a case the dependence for $k_{\tau l}$ under border conditions of first type is:

$$
k_{\tau l}=\frac{\lambda R}{a \tau} 0,594 F_{0}^{0,42} .
$$

The value of the heat transfer coefficient of coal $\alpha$ for a separate piece of coal under border conditions of third type in formula (6) is calculated in accordance 
with dependence listed in work [11]. Taking into account the fact that Prandtl number for air is equal to 0,72 , we get:

$$
\alpha=0,203 \frac{\lambda_{v} R e^{0,561}}{R},
$$

where $\lambda_{v}$ - the coefficient of air heat conductivity, $W /\left(m \cdot{ }^{\circ} \mathrm{C}\right) ; R e$ - the Reynolds criterion.

$$
R e=\frac{V_{0} R}{v}
$$

where $V_{0}$ - the relative velocity of air within face, $\mathrm{m} / \mathrm{s}$;

$v$ - the kinematic viscosity of air, $\mathrm{m}^{2} / \mathrm{s}$.

The relative velocity of air upon the surface of coal piece that moves within air stream is equal to:

$$
V_{0}=V_{i} \pm V
$$

where: $V$ - the air velocity within face, $\mathrm{m} / \mathrm{s}$.

The sign "+" in formula (20) corresponds to counterflow of coal and air (ascending ventilation of face), while "-" - is of homotropal ventilation (descending ventilation). The velocity of air within face depends on the angle of seam's slope and is defined by formula [12]:

$$
V_{i}=3,15+0,15(\psi-45)
$$

The emission of coal heat within face, $W$, are equal to:

$$
Q=q_{0} F
$$

where: $F$ - the hewed coal surface area of heat exchange, $m^{2}$.

If in formula (22) we substitute $q_{0}$ with its value from expression (12), we will get:

$$
q_{0}=k_{\tau l} F\left(T_{0}-t\right) .
$$

The area of surface heat exchange between coal and air within face depends on daily rate of mining and is calculated by formula:

$$
F=\frac{3 A_{f} \tau}{j R},
$$

where $A_{f}$ - the traffic volume of coal in face, t/s;

$j$ - the density of coal, $\mathrm{kg} / \mathrm{m}^{3}$. 
The duration of heat exchange between hewed coal and air depends on the speed of fossil's movement within face:

$$
\tau=\frac{L_{c}}{V_{i}},
$$

where $L_{c}$ - the angled length of the face, $m$.

The average weighted radius of coal pieces is defined in dependence with the angle of slope by the following formula [13]:

$$
R=\frac{\psi}{2000(0,205 \psi-7,2)},\left(35^{\circ}<\psi<90^{\circ}\right)
$$

\section{The Peculiarities of Heat Exchange in Faces}

In the faces using combining and particularly pneumatic hammer coal extraction the actual surface of heat exchange between coal massif and air is significantly bigger, than it has been considered earlier. This is related to the fact the exposed surface of coal massif in such faces increases due to zigzag of working face (fig. 2). Thus, the heat exchange surface should be taken with account of its increasing due to the surface of benches, the width of which makes $2,7 \mathrm{~m}$.

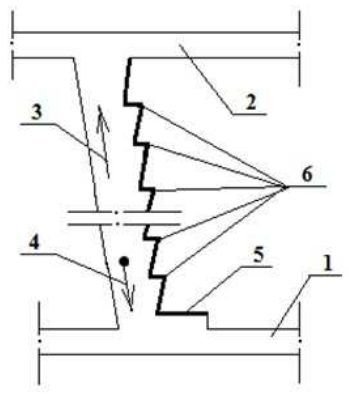

Figure 2:The diagram of pneumatic hammer face with overhead form of working area: 1 - haulage drift; 2 - ventilation drift; 3 - intake air; 4 direction of hewed coal movement; 5 - bench No. 1; 6 - working benches.

The width of first bench is bigger, than the width of the subsequent ones, and according to specifications on working areas, it makes up to 20-25 m. The estimated length of wide line in case of pneumatic hammer and combining faces can be represented as:

$$
L_{p}=L_{H}+B N_{V}+A
$$


where $L_{p}$ - the gaged length of the face, $m$;

$L_{H}$ - the slope distance of the face, $m$;

$N_{V}$ - number of benches within the face;

$B$ - the width of bench, $B=2,7 \mathrm{~m}$. as for faces using pneumatic hammer extraction of coal;

$A$ - the bench No. $1, A=3 \mathrm{~m}$. as for faces using combining extraction of coal; $A=20-25 \mathrm{~m}$. as for faces using pneumatic hammer extraction of coal.

In such a way, in case of seam's thickness of 1,0 m., hammer face's length of 120-140 m. and presence of 10 benches within it the heat-exchange surface of coal seam is $35-40 \%$ bigger, than it has been considered by dependences listed in [1].

When developing pneumatic hammer and combining faces, the main method of top roof regulation is the smooth lowering or retention the smooth dipping or retention on cogs. In such a case the heat transfer of air flow passing within the near-bottom area of face takes place mainly in interaction with exposed surfaces of roof, soil and coal seam, while the heat flow from mined-out space is almost absent. Consequently, in the formula for average weighted coefficient of unsteady heat exchange in faces developing steep coal seams the latter component taking account of heat transfer from outside stripped area can be omitted, due to which the formula gets the following form [1]:

$$
k_{\tau l}=k_{\tau z} \frac{U_{z}}{U}+k_{\tau k} \frac{U_{k}}{U}+k_{\tau p} \frac{U_{p}}{U}
$$

where: $k_{\tau l}$ - the average weighted value of coefficient of unsteady heat exchange for the near-bottom area of face, $W /\left(m^{2} \cdot{ }^{\circ} C\right)$;

$k_{\tau z}, k_{\tau k}, k_{\tau p}$ - the coefficients of unsteady heat exchange for, respectively, coal face, roof and soil, $W /\left(m^{2} \cdot{ }^{\circ} C\right)$;

$U$ - the common perimeter of cross section of face, $m$;

$U_{z}, U_{k}, U_{p}$ - the lengths of cross section areas for, respectively, coal face, roof and soil, $m$.

The calculations of air temperature within faces with steep seams using combining and pneumatic hammer extraction are performed by the formulae of method [1], in which indexes $A, E$ and $T$ used in regulating roof by smooth dipping and retention on cogs are substituted with values of unsteady heat exchange coefficient calculated in accordance with (28), while instead of value for face length there should be its gaged length calculated in accordance with (27). 


\section{Discussion}

Results of calculations of heat emissions from hewed coal within faces with slope angle of $40-88^{\circ}$, traffic volume of 10-60 t/h and air velocity of $2 \mathrm{~m} / \mathrm{s}$, obtained in accordance with suggested dependences, are represented in fig. 3.
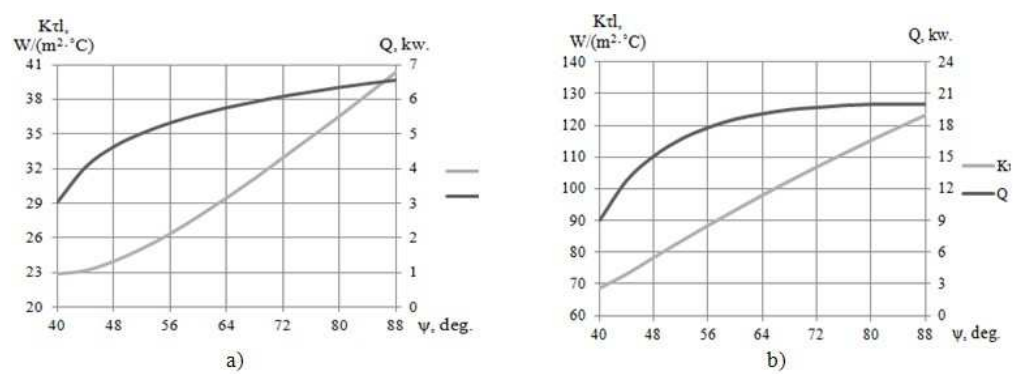

Figure 3: The value of coefficient of unsteady heat exchange between hewed coal and air $\left(k_{\tau l}\right)$ and heat emissions from coal $(Q)$ within face in accordance with the angle of seam's slope $(\psi)$ in case of coal traffic volume equal to 40 $\mathrm{t} / \mathrm{h}$ : a) the border conditions of third type, b) the border conditions of first

type

The calculations revealed that with increasing of seam's slope angle under conditions of both types there is growth of unsteady heat exchange coefficient value and, consequently, of heat emissions from coal. It should also be noted that under border conditions of first type the heat emission is about 3 times higher, than under border conditions of third type. The relative velocity of air upon the surface of coal pieces also grows with increasing of seam's slope angle. However the average weighted diameter of coal pieces in case of such increasing reduces and makes $0.04-0.008 \mathrm{~m}$. in denoted range. The area of heat exchange between coal and air within faces with increased traffic volume grows, while in case of increasing slope angle it reaches its maximum value at, approximately, $56^{\circ}$.

For the purpose of assessment of impact of heat emissions from coal on the temperature of air within face there are calculations performed in accordance with method [1] with account of obtained dependences, the results of which are represented in fig. 4. The calculations have been performed for the following conditions: the slope distance of face makes $140 \mathrm{~m}$; seam's slope angle $-60^{\circ}$; thickness of seam - 0,9 m; the air output within face has been taken according to the average velocity of air stream $(1 \mathrm{~m} / \mathrm{s})$; temperature and relative humidity at the entry to face has been taken as $20^{\circ} \mathrm{C}$ and $90 \%$ respectively. The calculations have been performed under temperature head between temperature of refuses 
and air in face within the range $10,0-18,6{ }^{\circ} \mathrm{C}$ and border conditions of third type.

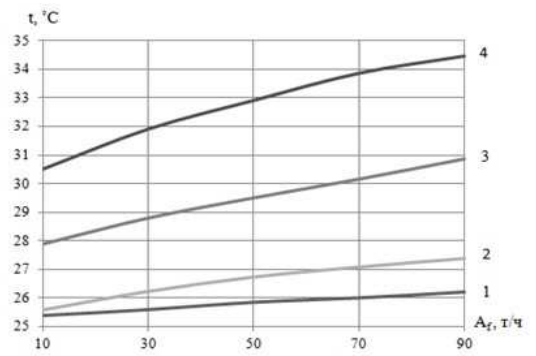

Figure 4: Diagrams of change of air temperature at the output of face $(t)$ depending on coal traffic volume $\left(A_{f}\right): 1$ - under temperature head between rocky massif and air in face $10,0^{\circ} \mathrm{C} ; 2-12,9^{\circ} \mathrm{C} ; 3-15,7^{\circ} \mathrm{C} ; 4-18,6^{\circ} \mathrm{C}$.

Analysis of obtained results showed that in case of increased traffic volume of coal the air temperature at output grows. This is stipulated with increase of the surface of heat exchange between hewed coal and air stream within face. The higher the in-situ temperature of rocky massif, the bigger the impact that flow of falling coal possesses as on the air temperature within face. Analysis of heat balance in combining and hammer faces with different ways of top regulation revealed that starting from temperature head of $10,0^{\circ} \mathrm{C}$ the share of heat produced by hewed coal is being higher, than it can be due to extracting mechanisms, and under temperature head of $25,0^{\circ} \mathrm{C}$ it makes up to $30 \%$ in total heat balance of working area. At the same time, in cases when the developed seam is drowned or when coal extraction is performed together with moistening (and coal surface gets wet), which falls under border conditions of first type, the heat emissions from coal make up to $50 \%$ of heat balance.

\section{Conclusions}

The paper provides calculated dependences for defining heat emissions from coal in faces developing steep coal seams with combining and pneumatic hammer technologies of coal extracting. There is an analysis of heat exchange in such faces when regulating top by smooth dipping with retention on the cogs, and as the result the calculated dependences for defining coefficient of unsteady heat transfer between rock massifs and air in the faces are represented. It is revealed that heat emissions from coal in the faces with steep occurrence of seams possess significantly bigger impact on the temperature conditions of working faces, than 
it was considered before. The heat emissions grow with increase of depth of development and load on wall and can make 30-50\% in total heat balance of working face. The obtained dependences can be recommended for practical applying [14].

\section{References}

[1] V.A. Cousin, A.Velichko, N.N. Hohotova, Common Methodology for Predicting Temperature Conditions in Coal Mines, MakNII, Makeyevka-Donbass, (1979), 196.

[2] A.N.Shcherban, Mine Cooling Guide, China Coal Industry Publishing House, China, Beijing, (1982).

[3] Zhu Shuai, ShiyueWu, Cheng Jianwei, Li Siyuan, Li Mingming, An Underground AirRoute Temperature Prediction Model for Ultra-Deep Coal Mines, Minerals, 5, (2015), 527-545.

[4] A. Martynov, N. Maleyev, A. Yakovenko, Software for Thermal Calculation to Plan Control Measures Against High Air Temperature in Deep Mines; Mining Information and Analytical Bulletin (Scientific and Technical Journal), Russia, 10, (2015), 228-237.

[5] Qin Yueping, Kong Song, Liu Wei, Jiang Zhenjun, Wu Jiansong, Calculation of the Chilling Requirement for Air Conditioning in the Excavation Roadway, Journal of Engineering Science and Technology Review, 8 (3), (2015), 91-97.

[6] V. Alabyev, A. Yakovenko, Underground Mining Refrigerating Complex of 1MW Capacity, Food Production Technologies and Equipment: Collection of Scientific Papers, Donetsk: DonDUET, 11, (2004), 42-50.

[7] V.Alabyev, A. Yakovenko, A. Klimov, Acceptance Test Results for the Mobile Mine Air Conditioner KPSh 300 Prototype, Means for Creating Safe and Healthy Working Conditions in Coal Mines: Collection of Scientific Papers. Makeyevka: MakNII, Ukraine, 20, (2008), 99-109.

[8] Products and services, http://www.wat-klima.com/en/products-services-23.html.

[9] Mine cooling system. Technical information, http://www.siemagtecberg.com/cms/upload/downloads/en/TI_19_Mine-Cooling-System_e.pdf.

[10] A.V. Lykov, Thermal conductivity theory, Vysshaya Shkola, Moscow, (1967), 600.

[11] S.S. Kutateladze, Basics of thermal conductivity theory, Nauka, Moscow-Novosibirsk, (1970), 658

[12] I.E. Bolbat, A.F. Voziyanov, V.F. Butt et al., Research of coal velocity in the mining faces of steep benches, Issues of ventilation and safety in coal mines: A Book, Part 2, Donbass, Donetsk, (1970).

[13] G.A. Pozdnyakov, N.I. Zhilyaev, I.N. Bokaev, S.N. Aleksandrov, Study of dust features of the mining faces of steep benches with hammer extraction, Gas dust and emission control in coal mines: A Book, Makeev State Research Institute, 8, Makeevka, (1972).

[14] Prediction and normalization of thermal conditions in coal mines: SOU-N 10.1.00174088.027-2011, Official view. Kiev, Ministry of Fuel and Energy of Ukraine, (2011), 188. 